\title{
Correction to: An Evaluation of Adjuvant Psychological Therapy (APT) Effectiveness on the Quality of Life of Patients with Hematologic Malignancies
}

\author{
Masoome Barani ${ }^{1} \cdot$ Maryam Bakhtiari $^{2} \cdot$ Vahid Sadeghi Firoozabadi $^{3} \cdot$ Mahshid Mehdizadeh $^{4} \cdot$ Akram Sadeghi $^{5}$
}

Published online: 3 February 2018

(C) Springer Science+Business Media, LLC, part of Springer Nature 2018

\section{Correction to: Curr Psychol https://doi.org/10.1007/s12144-017-9716-3}

The original version of this article unfortunately contained a mistake. One of the authors' name Mahshid Mehdizadeh is wrongly written as Mahshid Mahdizadeh.

The original article has been corrected.

The online version of the original article can be found at https://doi.org/ $10.1007 /$ s12144-017-9716-3

Vahid Sadeghi Firoozabadi

Sadeghi_Firoozabadi@yahoo.com

1 Department of Clinical Psychology, Faculty of Medical Science, Shahid Beheshti University of Medical Sciences, Tehran, Iran

2 Department of Psychiatric, Taleghani Hospital, Shahid Beheshty University of Medical Science, Tehran, Iran

3 Psychology and Cancer Research Center, Educational Sciences and Psychology Faculty, Shahid Beheshti University, Tehran, Iran

4 Children's Hematology Department, Taleghani Hospital, Tehran, Iran

5 Science and Research Branch, The Islamic Azad University, Tehran, Iran 